\title{
AFFECTIVE STATES INFLUENCE SPORT PERFORMANCE IN SWIMMING
}

\author{
ALEKSANDRA SAMEŁKOㅁ, MONIKA GUSZKOWSKA², ANNA GALA-KWIATKOWSKA ${ }^{1}$ \\ IJózef Pitsudski University of Physical Education in Warsaw, Faculty of Physical Education, Department of \\ Pedagogy and Psychology, Warsaw, Poland \\ 2Józef Pitsudski University of Physical Education in Warsaw, Faculty of Rehabilitation, Department of Clinical \\ Psychology and Special Education, Warsaw, Poland
}

\author{
Mailing address: Aleksandra Samełko, Józef Piłsudski University of Physical Education in Warsaw, \\ Faculty of Physical Education, 34 Marymoncka Street, 00-968 Warszawa, tel.: +48 22 8340431, fax: +48 22 8651080, \\ e-mail:al.samelko@gmail.com
}

\begin{abstract}
Introduction. Sports activity involves experiencing affective states, which have a substantial effect on actions taken by the athlete. The results of previous studies on the relationship between emotional states and sport performance outcomes are ambiguous. The aim of the study was to establish the relationships between affective states (both emotional states and moods) and performance in swimming. Material and methods. The study examined 9 female swimmers and 22 male swimmers competing at the national level aged from 15 to 23 years $(\mathrm{M}=18.1$; $\mathrm{SD}=2.397)$. Affective states were evaluated by means of the Profile of Mood States (POMS) completed once a day before the competition and the Positive and Negative Affect Schedule (PANAS) completed before each race. The subject's life record was divided by the time obtained in each race and expressed as a percentage. Results. Immediately before the races where the best results were obtained, the swimmers experienced the strongest positive emotions and the lowest level of negative emotions. The lowest level of positive states was recorded before the races with the worst performance. The lower the level of negative moods (fatigue, depression, anger, and tension) and the higher the level of positive moods (vigour and kindness) were, the better the results obtained by swimmers were. One exception was confusion, which unexpectedly correlated positively with the swimmers' results. Preliminary analyses showed no indication of statistically significant differences between the women and men surveyed. Conclusions. The results of the study suggest that affective states influence performance outcomes in swimming. This influence may vary according to the valence and content as well as duration of affective states (emotional states vs. mood). On the basis of the results obtained, guidelines for coaches and their athletes can be formulated. A properly prepared trainer can choose training tasks in such a way as to optimise the intensity and content of the emotions experienced by athletes. Emotions seem to be important not only with regard to athletes' well-being, but also as indirect and direct predictors of the results they achieve. Expression of emotion and emotional awareness in persons connected with sport should be included in training work.
\end{abstract}

Key words: emotional states, mood, sports competition, swimming

\section{Introduction}

Sports activity involves experiencing affective states [1]. Emotions connected with sport are noticeable, strong, varied, and very dynamic, especially during competitions [2]. They have a substantial effect on actions taken by the athlete [3]. Affective states experienced by the athlete before and during competitions are also strongly correlated with sports performance $[4,5]$. Sports performance is determined not only by the level of emotional arousal during the competition but also by the content of the affective states experienced by the athlete [6].

The first researcher who found a relationship between affective states and sports performance was Morgan [7]. He demonstrated that athletes who obtained the best results were characterised by a lower level of negative moods (tension, confusion, depression, anger, and fatigue) and a higher level of positive mood (vigour) than athletes with lower sport achievements. The mood profile resembled the shape of an iceberg. Vigour was above the water surface (i.e., the population mean) and negative moods were below the water surface, hence the term "iceberg profile". The worst sports results were obtained by athletes with an inverted iceberg profile, that is a low level of vigour and a high level of negative moods. Since its first presentation, the iceberg model has often been verified [8] and has been at least partially confirmed empirically in athletes representing various sports and performance levels [e.g., 9, 10, 11, 12, 13]. The results of the studies of athletes from various disciplines also confirm the usefulness of the Profile of Mood States (POMS), the scale used by Morgan, in predicting sports performance [14, 15]. Particularly noteworthy are the results documented by Ekici [16] in a study of 440 athletes practising both individual and team sports. The athletes characterised by higher levels of positive moods obtained better results. The meta-analysis presented by Lane [8] demonstrated that mood profiles make it possible to predict the results of an athlete, regardless of his or her sports skill level. However, not all the data are consistent with the iceberg profile proposed by Morgan [17, 18]. Norlander and Archer [19] did not confirm that emotional states before races were related to outcomes in swimming. The results of a meta-analysis of 33 studies on relations between POMS values before competitions and sports results indicated that mood states only accounted for $1 \%$ of the variation in sports performance [20]. The results of previ- 
ous studies on the relationship between emotional states and sports results are thus ambiguous.

In our opinion, one source of ambiguity in the results of the above-mentioned research is the duration of the affective state. Authors rarely made the distinction between emotional states and moods. Using the Profile of Mood States to study affective states, Morgan [7] focused on the latter. Emotional states are triggered by specific stimuli (for example, participation in a particular race) and persist for a short time. Mood is more diffuse and free-floating; it is harder to identify its cause, and it can last for several days [21, 22]. It is not known whether the relationships between athletic performance and mood can be generalised to emotions. It remains unclear what the relationship between the emotional state immediately before the race and its outcome is and whether good results are accompanied by a low level of negative emotional states and a high level of positive ones, as suggested by the iceberg model. According to Martinent, Nicolas, Gaudreau, and Campo [23], strong emotions have a positive effect regardless of whether they are positive or negative. Studies of marathon runners demonstrated that anger, frustration, or irritation may sometimes lead to increased arousal and therefore improve sports performance [24]. Brandt et al. [25] argue that a moderate increase in tension and anger during competitions can have a positive effect on performance. These results are not consistent with Morgan's observations regarding moods [7]. These dependencies between emotions and sports performance seem to us to be more complex.

Another factor that should be taken into account is the sport discipline [26]. The influence of emotional states on sports performance may vary depending on how long the contest lasts. In the case of short-distance running, the emotional state at the time of starting the run is important. When a competition lasts a long time (for example, in tennis), emotional states may change depending on how the competition unfolds. The situation is even more complicated when an athlete competes several times per day, as is the case in swimming. The results of previous races may affect the emotional state before the next ones. In such situations, the mood experienced on a given day may be less important, and the emotional state immediately before each race may have a greater impact on the results. The findings of Lane, Thelwell, and Devonport [27] suggested that mood states were associated with performance, but the nature of these relationships was situation-specific.

The aim of this study was to establish the relationships between affective states (both emotional states and moods) and sports performance in swimming.

\section{Material and methods}

\section{Participants and measures}

The study examined 9 female swimmers and 22 male swimmers competing at the national level aged from 15 to 23 years $(\mathrm{M}=18.1 ; \mathrm{SD}=2.397)$ with at least five years of experience in swimming $(\mathrm{M}=8.2$; $\mathrm{SD}=2.67)$. The swimmers trained in various sports clubs in Poland.

The characteristics of the group in terms of the best stroke are presented in Table 1.

Mood states were assessed using the Profile of Mood States (POMS) [28]. Such assessments are very often carried out in different populations [26]. The inventory is composed of 65 adjectives that determine current mood, with participants assessing the intensity for each adjective on a scale of 0 to 5 points. The adjectives form six scales: depression, tension, anger, fatigue, confusion, and vigour. The Polish version of POMS contains an
Table 1. The swimmers' best stroke

\begin{tabular}{|c|c|}
\hline Best stroke & N \\
\hline Freestyle & 11 \\
\hline Butterfly & 3 \\
\hline Backstroke & 8 \\
\hline Breaststroke & 4 \\
\hline Medley & 5 \\
\hline
\end{tabular}

additional scale of kindness [29]. The reliability coefficients of the Polish version estimated using the split-half method ranged from 0.73 (vigour) to 0.85 (fatigue). Theoretical accuracy was determined by checking intergroup differences, comparing the results obtained by patients of psychiatric clinics, dentists, students, drivers, and industry employees. The directions of these differences are in line with expectations and confirm the theoretical validity of the tool [30].

Emotional states experienced immediately before the competition were measured using the Positive and Negative Affect Schedule (PANAS), in its Polish adaptation by Brzozowski [31]. It contains scales of positive and negative affect. In the version used in the study, each scale consists of 10 adjectives evaluated on a scale from 1 to 5 . The subjects indicate to what extent the adjective describes their current emotional state. The reliability of the scale is satisfying: Cronbach's alpha coefficients range from 0.73 to 0.95 depending on the version and type of the sample. The validity of the scale has been confirmed by factor analysis, cluster analysis, correlation with other tools, and intergroup differences.

Data on the life record in each type of swimming competition were obtained from the respondents. We also recorded the results achieved in selected competitions held during the study. The subject's life record was divided by the time obtained in these competitions and expressed as a percentage. A performance percentage score above 100 means that during the competition, the competitor obtained a result that was better than the life record.

\section{Procedure}

Before the study began, we organised meetings with the trainers and athletes in sports clubs in order to present the purpose of the research and invite them to participate.

The measurements were carried out during three tournaments at various sport levels (national winter Polish championships in Ostrowiec Świętokrzyski and two Grand Prix tournaments in Kraków and Łódź in 2014). Each competition lasted from three to five days. The same subjects participated in the study each time. The athletes completed the POMS once a day, in the morning. In addition, no more than an hour before each race, the athletes completed the PANAS. We collected 232 selfassessments of mood states (POMS), 164 for men and 68 for women, and 362 self-assessments of emotional states before the races (PANAS), 248 for men and 114 for women. The number of POMS assessments per swimmer ranged from 6 to 12, depending on the number of days on which athletes participated in the competition. The athletes completed the PANAS scale from 12 to 24 times, depending on how many races they competed in.

\section{Statistical analysis}

The performance percentage scores were divided into four quartiles. The first quartile included results from 88.01 to 97.01, which were significantly worse than personal bests $(M=95.95$; 
$\mathrm{SD}=1.47$ ). The second quartile consisted of results which were slightly worse than personal bests and ranged from 97.50 to 99.01 $(\mathrm{M}=98.58$; $\mathrm{SD}=0.57)$. The third quartile contained scores from 99.53 to 100.00 , that is scores similar to personal bests $(\mathrm{M}=100.08$; $\mathrm{SD}=0.32)$, whereas the fourth quartile included results that were better than the personal bests (from 100.75 to $117.5 ; \mathrm{M}=102.39 ; \mathrm{SD}=2.30$ ). In the preliminary analyses, it was established that men and women did not differ in terms of the results obtained. The proportions of women and men in the quartiles distinguished on the basis of the results as well as the relationships between affective states and sports results were similar. For these reasons, the results for both sexes were presented together.

The athletes completed the POMS once a day before the competition. As they usually competed in more than one run, the performance percentage scores obtained on a given day were averaged. Correlation coefficients between the averaged performance percentage scores and mood indices were calculated. Non-parametric tests (Kruskal-Wallis, Mann-Whitney, and Spearman's rank correlation) and stepwise regression analysis were used. The results at a level of $\mathrm{p}<0.05$ were considered statistically significant. Statistical analyses were performed using statistical software (SPSS, version 22).

\section{Results}

Preliminary analyses showed no indication of statistically significant differences between the women and men surveyed.

In order to establish the relationship between emotional states and sports results, the PANAS scores before the races qualified for the first, second, third, and fourth quartiles were compared (Table 2). The intensity of emotional states, both positive and negative, varied depending on the sports results obtained during competitions. The highest intensity of positive emotional states was recorded before the races in which the best sports results were obtained. The lowest levels of negative emotions were documented before the races with the best performance, whereas their highest level was recorded before the races with results similar to the personal best.

Furthermore, the correlation coefficient between sports outcomes and the intensity of positive emotions ( rho $=0.333$; $\mathrm{p}<0.001$ ) and negative emotions ( $\mathrm{rho}=0.005 ; \mathrm{p}=0.926)$ were computed. The higher the positive emotional state measured before the race was, the higher the result obtained in the race was. The result obtained during the swimming competition was not correlated with the level of negative emotions.

The indicator of the sports level was the place obtained in the competition by a given athlete in a specific stroke and at a certain distance. On this basis, three levels were distinguished in a given competition: a high level (from $1^{\text {st }}$ to $10^{\text {th }}$ place), a medium level (11 th to $20^{\text {th }}$ place), and a low level (21 st place or lower). This classification was based on the generally accepted principle related to organising the A and B finals during the Polish championships.

Stepwise regression analysis was used to determine whether emotions experienced immediately before the race make it possible to predict the results obtained. Only the intensity of positive emotions before the race turned out to be a significant (and positive) predictor of the results $(\beta=0.303)$, but it allowed for the prediction of merely $9 \%$ of them $\left(R^{2}=0.089 ; F=35.36\right.$; $\mathrm{p}<0.001$ ). The intensity of negative emotions did not allow for the prediction of performance. The results obtained on a single day were averaged. Furthermore, the correlation coefficients between mood states measured once a day (before the contest) and sports performance were calculated (Table 3 ).

The correlations were significant but moderately weak for fatigue, depression, and confusion. Although other correlation coefficients for negative states such as anger and tension were statistically significant, they showed very poor correlations between negative mood states on a competition day and performance. Similar patterns were observed for positive moods, that is vigour and kindness. The lower the level of negative moods and the higher the level of positive moods were, the better the results obtained by the swimmers were. One exception was confusion, which unexpectedly correlated positively with sports results. As demonstrated by the results of the stepwise regression analysis, $10 \%$ of averaged results could be predicted $\left(\mathrm{R}^{2}=0.103\right.$; $\mathrm{F}=14.45 ; \mathrm{p}<0.001)$ based on three mood states: depression $(\beta=-0.313)$, fatigue $(\beta=-0.211)$, and confusion $(\beta=0.191)$. Better sports results can be expected in swimmers characterised by lower levels of depression and fatigue on a competition day, and, surprisingly, higher levels of confusion.

Table 2. Intensity of emotional states before races in groups with different performance outcomes

\begin{tabular}{|c|c|c|c|c|c|}
\hline & $1^{\text {st }}$ quartile & $2^{\text {nd }}$ quartile & $3^{\text {rd }}$ quartile & 4 $^{\text {th }}$ quartile & Kruskal-Wallis chi squared \\
\hline $\begin{array}{c}\text { Positive states } \\
(M \pm S D)\end{array}$ & $24.60 \pm 9.6$ & $28.14 \pm 9.0$ & $32.31 \pm 7.1$ & $32.45 \pm 7.6$ & 44.369 \\
\hline $\begin{array}{c}\text { Negative states } \\
(M \pm S D)\end{array}$ & $15.00 \pm 5.6$ & $14.97 \pm 5.2$ & $16.64 \pm 5.7$ & $14.50 \pm 5.2$ & 10.928 \\
\hline
\end{tabular}

$1^{\text {st }}$ quartile - results significantly worse than personal bests; $2^{\text {nd }}$ quartile - results slightly worse than personal bests; $3^{\text {rd }}$ quartile - results similar to personal bests; $4^{\text {th }}$ quartile - results better than personal bests.

Table 3. Spearman's rank correlations between performance outcomes and mood states

\begin{tabular}{|c|c|c|c|c|c|c|c|}
\hline & Fatigue & Depression & Confusion & Anger & Tension & Vigour & Kindness \\
\hline Sports performance & $-0.322^{* *}$ & $-0.260^{* *}$ & $0.231^{* *}$ & $-0.173^{*}$ & $-0.147^{*}$ & $0.197^{*}$ & $0.134^{*}$ \\
\hline
\end{tabular}

${ }^{*}=\mathrm{p}<0.005 ;{ }^{* *}=\mathrm{p}<0.001$. 


\section{Discussion}

The present study attempted to find the relationships between affective states and the results obtained by swimmers during competitions. They can be predicted by Morgan's iceberg model [7] and based on the results of previous studies of athletes from various sports [5, 10, 16, 25, 32, 33, 34].

The evidence for the relationships between emotional states experienced just before a race and sports results achieved in that race was provided by both comparative and correlation analyses. Immediately before the races where the best results were obtained, the swimmers experienced the strongest positive emotions and the lowest level of negative emotions. The lowest level of positive states was recorded before the races with the worst performance. These results are consistent with the relationships described in Morgan's iceberg model [7]. However, it should be emphasised that this part of our results concerns affective states of shorter duration, that is emotional states, rather than moods, which were examined by Morgan. The findings are not consistent with previous reports, which demonstrated that both positive and negative emotions release energy and can lead to increased efficiency of actions [23, 24]. Correlation analyses suggest that sports performance is more related to positive emotional states than to negative ones. Only positive emotional states experienced before races correlated with swimming performance and only the intensity of positive emotions was its predictor. The importance of positive emotions as determinants of sports performance was previously noted by Ekici [16]. Studies have shown that experiencing positive emotions prevents increases in anxiety and loss of concentration [35]. Vallerand and Blanchard [21] showed that positive emotions (excitement and happiness) were more closely associated with concentration than negative ones. Positive emotions also correlate with selfconfidence [36]. Furthermore, conscious experiencing of positive emotions increases the effectiveness of coping with stress [37].

A different pattern was observed for the mood states before sports competitions in the current study. All the mood states were significantly correlated (although not very strongly) with the results achieved. The data obtained in the group of swimmers seem to be consistent with the iceberg profile. The only exception was confusion, whose positive correlation with the results is surprising. It is worth emphasising that previous studies have provided data that were consistent with Morgan's statements [10, 25, 33, 38, 39] and ones which were not [40]. The strongest correlations were found in the case of fatigue, depression, and confusion. The importance of depression was emphasised by Lane and Terry [33], who demonstrated that it intensifies other negative affective states. Experiencing strong fatigue on a competition day may in turn be indicative of overtraining. These three mood states allowed for the prediction of the results obtained during the competition. In the case of fatigue and depression, the direction of the relationship was consistent with the prediction based on Morgan's model, with these factors being negative predictors of sports performance. As already mentioned, confusion unexpectedly turned out to be a positive predictor. This finding is difficult to explain. Confusion indicates unpleasant mood, and it is hard to find studies that demonstrate its positive effect on sports performance. Perhaps confusion was correlated with other situational factors connected with the athletes' participation in the competitions rather than with the race itself. Further research is needed to examine whether this finding should be considered an artefact or a surprising regularity.
Negative emotions, especially anger, may contribute to improving sports performance. Such emotions excite the nervous system, increasing heart rate and blood pressure, and evoke physiological responses [41, 42]. Therefore, anger is likely to contribute to an improvement in performance in sports where physiological mobilisation is critical. In sports where the efficiency of cognitive processes is important, anger can reduce the effectiveness of actions as it worsens concentration, leads to ineffective processing of information, and slows reaction time [43]. In our study, anger correlated negatively with sports performance (although less than the above-mentioned mood states), but it did not allow for predicting the results. The problem may be even more complex. According to Hanin [44], the mood experienced by the athlete is less significant than his or her attitude to feelings and the attitude towards the perception of such moods. The subjective assessment of anxiety experienced by athletes is more critical to their performance outcomes than the level of anxiety they actually feel [45]. We did not consider that issue in our research. This requires exploration in the future. We did not take into account the athletes' gender or the level of their sports skills, which is a significant limitation of our research. In previous studies, researchers did not always precisely distinguish between the concepts of emotion and mood. In our study, we compared the relationships of sports performance with affective states of varying duration, that is emotions and moods. It turned out that they were similar; correlation coefficients, beta coefficients, and determination coefficients had similar values. Ten percent of the results obtained by the swimmers could be predicted both based on emotional and mood states. Diment and Terry [46] also showed that mood variables accounted for a significant proportion of the variability in swimming performance. Not only sports psychologists but also sports theorists are in agreement that positive and negative emotions are correlated with sports performance $[47,48]$.

Our research has several limitations. The first limitation is the small sample size and unequal sex ratio. Further studies involving more swimmers at different sports levels are required. The second important limitation is treating each race as an independent event; the results obtained in an earlier race affect the emotional state before the next run. The data obtained in our study could be additionally analysed in this respect. Further research should also take into account the psychological characteristics of athletes (personality, emotionality, and temperament). It would also be interesting to study the relationship between the emotional state and the level of an athlete's physical, mental, and tactical preparation for the competition. Legrand and LeScanff [49] as well as Calmeiro and Tenenbaum [9] also emphasised the need to conduct idiographic research, taking into account the profiles of mood states in individual athletes.

\section{Conclusions}

The results of our research confirm the observations of other researchers that affective states influence sports performance. The influence of affective states on performance in swimming probably varies according to their valence and content as well as the duration of emotional phenomena (emotional states vs. mood). Performance outcomes were significantly related only to the intensity of the positive emotional state experienced by the athlete immediately before the race. Both positive and negative moods were related to the results obtained on a given day of the competition. Our results confirm that it is important to gain better insight into pre-competitive emotional states. Emotions should be a significant area of the mental preparation of 
an athlete [50]. Persons who experience lower intensity of negative emotions and higher levels of positive emotions before the competition achieve better results. It should be remembered that the optimal mood profile may be different for individual athletes. This is suggested by Hanin's Individual Zones of Optimal Functioning model [44]. What's more, these profiles can also differ intra-individually. In further studies, an idiographic approach analysing the diversity of an athlete's performance level depending on the affective states experienced may be more useful.

\section{Acknowledgements}

The research was funded by the Polish Ministry of Science and Higher Education as part of the "Performance outcomes, affective states, and personality determinants in swimmers" project (Project No. DM-33).

\section{Literature}

1. Cohen A.B., Tenenbaum G., English W.R. (2006). Emotions and golf performance. Behavior Modification 30, 259-280.

2. Vast R.L., Young R.L., Thomas P.R. (2010). Emotions in sport: Perceived effects on attention, concentration, and performance. Australian Psychologist 45, 132-140.

3. Wagstaff Ch.R.D. (2014). Emotion regulation and sport performance. Journal of Sport and Exercise Psychology 36, 401412.

4. Lane A.M., Beedie C.J., Jones M.V., Uphill M., Devonport T.J. (2012). The BASES expert statement on emotion regulation in sport. Journal of Sports Sciences 30, 1189-95.

5. McCarthy P. (2011). Positive emotion in sport performance: Current status and future directions. International Review of Sport and Exercise Psychology 4, 50-69.

6. Sève C., Ria L., Poizat G., Saury J., Durand M. (2007). Performance-induced emotions experienced during highstakes table tennis matches. Psychology of Sport and Exercise 8, 25-46.

7. Morgan W.P. (1980). Test of champions: The iceberg profile. Psychology Today 14, 92-108.

8. Lane A.M. (2000). Mood and emotion in sport: A response to Jones, Mace, and Williams (2000). Perceptual and Motor Skills 91, 649-652.

9. Calmeiro L., Tenenbaum G. (2007). Fluctuations of cognitive-emotional states during competition: An idiographic approach. Revista de Psicología del Deporte 16, 85-100.

10. De la Vega-Marcos R., Ruiz-Barquín R., Tejero-González C., Rivera-Rodriguez M. (2014b). Relationship between moods and performance in high level male volleyball. Revista de Psicología del Deporte 23, 49-56. [in Spanish]

11. Devonport T., Lane A., Hanin Y. (2005). Emotional states of athletes prior to performance-induced injury. Journal of Sports Science and Medicine 4, 382-394.

12. Portela-Pino I., Gutierrez-Sanchez A., Alonso-Fernandez D., Abadia-Garcia de Vicuna O. (2017). Comparative study on pre-competition mood in Canadian and Spanish university students. Journal of Human Sport and Exercise 12, 13281336.

13. Raglin J.S., Morgan W.P., Luchsinger A.E. (1990). Mood and self-motivation in successful and unsuccessful female rowers. Medicine and Science in Sports and Exercises 6, 849853.
14. Beedie C.J., Terry P.C., Lane A. (2000). The profile of mood states and athletic performance: Two meta-analyses. Journal of Applied Sport Psychology 12, 49-68.

15. Palacios M.P., Gonzalez R.O., Aruza G.J., Arribas G.S., Izarusta A.S. (2015). Factorial invariance evaluation between the paper/pencil and online versions of Profile of Mood States (POMS) in a sample of athletes. Revista Mexicana de Psicología 32, 48-56.

16. Ekici S. (2011). The effect of positive and negative mood on motivation to succeed of elite athletes. International Journal of Human Sciences 8(2), 946-962.

17. Hassmen P., Blomstrand E. (1995). Mood state relationships and soccer team performance. The Sport Psychologist 9, 297-308.

18. Lane A.M., Terry P.C., Beedie Ch.J., Curry D.A., Stevens M. (2004). Mood and concentration grid performance. Effects of depressed mood. Psychology of Sport and Exercise 2, 133-145.

19. Norlander T., Archer T. (2002). Predicting performance in ski and swim championships: Effectiveness of mood, perceived exertion, and dispositional optimism. Perceptual and Motor Skills 94, 153-164.

20. Rowley A.J., Landers D.M., Kyllo L.B, Etnier J.L. (1995). Does the iceberg profile discriminate between successful athletes? A meta-analysis. Journal of Sport and Exercise Psychology 17, 185-199.

21. Vallerand R.J., Blanchard C.M. (2000). Emotions in sport. Champaign: Human Kinetics.

22. Watson D. (2000). Mood and temperament. New York: Guilford Press.

23. Martinent G., Nicolas M., Gaudreau P., Campo M. (2013). A cluster analysis of affective states before and during competition. Journal of Sport and Exercise Psychology 35, 600611.

24. Carter L., Sachs M. (2012). In the mood: Flow, mood, and the marathon. Marathon and Beyond 16, 68-79.

25. Brandt R., da Silveira V.M., Segato L.L., Kretzer F., de Carvalho T., Andrade A. (2011). Relationship between mood states and sports performance of high-level sailors. Psicologia: Teoria e Prática 13, 117-130. [in Portuguese]

26. Brandt R., da Silveira Viana M., Crocetta T.B., Andrade A. (2016). Association between mood states and performance of Brazilian elite sailors. Winners vs. non-winners. Cultura Ciencia y Deporte 11, 119-125.

27. Lane A.M., Thelwell R., Devonport T.J. (2009). Emotional intelligence and mood states associated with optimal performance. Electronic Journal of Applied Psychology: General Psychology 5, 67-73.

28. McNair D.M., Lorr M., Droppelman L.F. (1971). Manual for the Profile of Mood States. San Diego: Educational and Industrial Testing Service.

29. Dudek B., Koniarek J. (1987). Adaptation of Profile of Mood States by D.M. McNair., M. Lorr, and L.F. Droppleman. Przegląd Psychologiczny 3, 753-762. [in Polish]

30. Watson D., Clark L.A., Tellegen A. (1988). Development and validation of brief measures of positive and negative affect. The PANAS Scales. Journal of Personality and Social Psychology 54, 1063-1070.

31. Brzozowski P. (2010). Positive and Negative Affect Schedule. SUPIN: a Polish adaptation of the PANAS scale by David Watson and Anna Clark. Warsaw: PTP. [in Polish]

32. De la Vega-Marcos R., Ruiz-Barquín R., Borges Hernández P.J., Tejero-González C. (2014a). New three- 
dimensional measure of sport mood state: POMS-VIC. Cuadernos de Psicología del Deporte 14, 37-46. [in Spanish]

33. Lane A.M., Terry P.C. (2000). The nature of mood. Development of a conceptual model with a focus on depression. Journal of Applied Sport Psychology 12, 16-33.

34. Lane A.M., Beedie C.J., Jones M.V., Uphill M., Devonport T.J. (2012). The BASES expert statement on emotion regulation in sport. Journal of Sports Sciences 30, 1189-95.

35. Chirivella E.C., Esquiva I.Ch., Tort B.E. (2015). Evidence of convergent and criterion validity in the application of the Emotion Evaluation Instrument in Sports Competitions. Revista de Psicología del Deporte 24, 311-316. [in Spanish]

36. Dias C., Cruz J.F., Fonseca A.M. (2014). Pre-competitive emotions in team sports. Differences across gender and perceived importance and difficulty of the competition. Revista Portuguesa de Ciências do Desporto 14(3), 81-96.

37. Tugade M.M., Fredrickson B.L., Feldman B.L. (2004). Psychological resilience and positive emotional granularity: Examining the benefits of positive emotions on coping and health. Journal of Personality 6, 1162-1187.

38. Lane A.M., Terry P.C., Beedie Ch.J., Curry D.A., Clark N. (2001). Mood and performance. Test of a conceptual model with a focus on depressed mood. Psychology of Sport and Exercise 2, 157-172.

39. Torres-Luque G., Hernandez-Garcia R., Olmedilla A., Ortega E., Garatachea N. (2013). Fluctuation of the Profile of Mood States of (POMS) in a competitive period in elite judokas. Revista de Psicología del Deporte 22, 313-320. [in Spanish]

40. Díaz J., Gutiérrez J.N., Hoyos J.A. (2015). Pre-competitive states of mood and sports results of bowling competitors. Cuadernos de Psicologíadel Deporte 15, 53-64. [in Portuguese]

41. Fredrickson B.L., Maynard K.E., Helms M.J., Haney T.L., Seigler C., Barefoot J.C. (2000). Hostility predicts magnitu- de and duration of blood pressure response to anger. Journal of Behavioural Medicine 23, 229-243.

42. Woodman T., Davis P.A., Hardy L., Callow N., Glasscock I., Yuill-Proctor J. (2009). Emotions and sport performance. An exploration of happiness, hope and anger. Journal of Sport and Exercise Psychology 31, 169-188.

43. Korobeynikov G., Korobeynikowa L., Mytskan B., Chernozub A., Cynarski W. (2017). Information processing and emotional response in elite athletes. Ido Movement for Culture. Journal of Martial Arts Anthropology 17, 41-50.

44. Hanin Y.L. (2000). Individual Zones of Optimal Functioning (IZOF) Model: Emotion-performance relationships in sport. In Y.L. Hanin (ed.), Emotions in sports (pp. 65-89). Champaign: Human Kinetics.

45. Hanin Y.L. (2003). Performance-related emotional states in sport: A qualitative analysis. Forum: Qualitative Social Research 4, 1. Retrieved on July 20, 2016, from http://www. qualitative research.net/fqs-texte/1-03/1-03hanin-e.html.

46. Diment G.M.,Terry P.C. (2003). Mood variability, personality and swimming performance. Australian Journal of Sport Psychology 55, 176.

47. Duarte L.H., Carbinatto M.V., Nunomura M. (2015). Artistic gymnastics and fear: Reflections on its causes. Science of Gymnastics Journal 7, 7-21.

48. Neil R., Bowles H.C.R., Fleming S., Hanton S. (2016).The experience of competition stress and emotions in cricket. The Sport Psychologist 30, 76-88.

49. Legrand F., LeScanff C. (2003). Tension-stress, effort-stress and mood profiling with an elite javelin performer. Psychology of Sport and Exercise 4, 429-436.

50. Fletcher D. (2006). British swimming, sport psychology, and Olympic medals. Is it all in the mind? American Swimming 2, 8-19.

Submitted: April 11, 2018

Accepted: June 6, 2018 